\title{
CITED4 mediates proliferation, apoptosis and steroidogenesis of Hu sheep granulosa cells in vitro
}

\author{
Xiaolei Yao ${ }^{1,2}$, M A El-Samahy,1,2, Shenhua Xiao ${ }^{1}$, Zhibo Wang ${ }^{1,2}$, Fanxing Meng 3 , Xiaodan Li ${ }^{1,2}$, \\ Yongjin Bao ${ }^{1,2}$, Yanli Zhang ${ }^{1,2}$, Ziyu Wang ${ }^{1,2}$, Yixuan Fan ${ }^{1,2}$ and Feng Wang ${ }^{1,2}$ \\ ${ }^{1}$ Iiangsu Livestock Embryo Engineering Laboratory, Nanjing Agricultural University, Nanjing, China, ${ }^{2}$ Hu Sheep \\ Academy, Nanjing Agricultural University, Nanjing, China and ${ }^{3}$ National Experimental Teaching Demonstration \\ Centre of Animal Science, Nanjing Agricultural University, Nanjing, China \\ Correspondence should be addressed to F Wang;Email: caeet@njau.edu.cn
}

\begin{abstract}
Being a novel target of luteinizing hormone (LH), the effect of CREB-binding protein/P300-interacting trans-activator with ED-rich tail member 4 (CITED4) gene on the proliferation, apoptosis, and steroidogenesis of ovarian granulosa cells (GCs) in Hu sheep was investigated. The presence of CITED4, CREB-binding protein (CBP), CCAAT/enhancer-binding protein alpha (C/EBPo) and -beta (C/ $E B P \beta)$ proteins was demonstrated in GCs and luteal cells. CITED4 protein in GCs was induced by LH, and CITED4 overexpression moderately increased GC responses to LH. In contrast, CITED4 knockdown in GCs decreased prostaglandin (PGE2)-induced LH target gene levels. Moreover, PGE2-stimulated CITED4 mRNA expression was blocked by ERK1/2 inhibition (U0126), suggesting that CITED4 is a downstream target of the ERK1/2 pathway in sheep GCs. In contrast to CITED4 knockdown, CITED4 overexpression promoted GC proliferation, inhibited apoptosis, upregulated cell cycle-related genes, and downregulated apoptosis-related genes. Additionally, CITED4 overexpression induced cell cycle transition from $S$ to G2/M phase. No effect was observed with CITED4 knockdown. CITED4 overexpression increased progesterone $\left(\mathrm{P}_{4}\right)$ production levels and STAR mRNA expression, whereas CITED4 knockdown decreased $\mathrm{P}_{4}$ production and STAR and $3 \beta$-HSD mRNA expression levels. Thus, our results suggest that CITED4 is involved in regulating the expression of LH-induced genes and the ERK1/2 pathway and the proliferation, apoptosis, and steroidogenesis in Hu sheep GCs by modulating the expression of related genes. These findings will help understand the role of CITED4 in follicular development and ovulation of pre-ovulatory follicles.

Reproduction (2021) $\mathbf{1 6 1} 255-267$
\end{abstract}

\section{Introduction}

In mammals, primary ovarian functions include mature oocyte production and steroids synthesis that support secondary sexual characteristics and pregnancy (Newman et al. 2008). Accumulating evidence indicates that ovarian granulosa cells (GCs) support follicle development and maturation by secreting steroids, growth factors, and cytokine factors (De Cesaro et al. 2018). GC proliferation is essential in the recruitment, selection, ovulation of follicles, and atresia (McGee \& Hsueh 2000). GC apoptosis can impair folliculogenesis, resulting in follicular atresia (Matsuda et al. 2012). Therefore, elucidating GC function is important for understanding follicular development and female fertility.

Folliculogenesis and ovulation are tightly regulated processes in which sequential responses are triggered by pituitary gonadotropins, follicle-stimulating hormone (FSH), and luteinizing hormone (LH) (Shimada \& Yamashita 2011, Hackbart et al. 2017). GCs respond rapidly to $\mathrm{LH}$, which affects the expression of $\mathrm{LH}$-induced genes that upregulate growth and transcription factors in vivo, to promote ovulation and luteinization (Carletti \& Christenson 2009). Notably, LH stimulates the mural GCs of pre-ovulatory follicles to secrete EGF family proteins, such as amphiregulin (AREG) and epiregulin (EREG), which are intra-follicular mediators of LH activity (Park et al. 2004). Similarly, in rodent GCs, expression levels of prostaglandin-endoperoxide synthase 2 (PTGS2), tumor necrosis factor-inducible gene 6 (TNFAIP6), and pentraxin 3 (PTX3) increased significantly after human chorionic gonadotropin (hCG) injection (Espey \& Richards 2002, Zhang et al. 2014). Recently, CREBbinding protein/P300-interacting transactivator with ED-rich tail member 4 (CITED4) was demonstrated as a novel LH-target for triggering ovulation through the ERK1/2 pathway. Transfection of CITED4 regulated the expression of LH-target genes in mouse GCs (Zhang et al. 2014), suggesting that CITED4 is required for stimulating $\mathrm{LH}$-target gene expression during follicular development and ovulation. However, CITED4 function 
during follicular development and ovulation in ruminant GCs of Hu sheep has not been thoroughly investigated.

CITED4 may regulate gene transcription and function by binding to CREB-binding protein (CBP)/p300 as a co-activator (Yahata et al. 2002). Moreover, CITED4CBP also binds to CCAAT/enhancer-binding protein beta $(\mathrm{C} / \mathrm{EBP} \beta)$, thereby promoting its transcriptional activity (Lee et al. 2010, Zhang et al. 2014). CITED4, $\mathrm{CBP}$, and C/EBP $\beta$ are highly expressed in mouse (Zhang et al. 2014) or porcine (Zhen et al. 2014, Yuan et al. 2018) GCs from pre-ovulatory follicles. C/EBP $\beta$ is an essential transcription factor for $\mathrm{LH}$-induced ovulation and luteinization (Fan et al. 2011). C/EBP $\beta$ also regulates porcine GC apoptosis and proliferation (Zhen et al. 2014, Yuan et al. 2018) and enhances estradiol $\left(\mathrm{E}_{2}\right)$ and progesterone $\left(\mathrm{P}_{4}\right)$ secretion (Zhen et al. 2014). Similar effects are observed in $P_{4}$ production by a human granulosa tumor cell line (Mizutani et al. 2014). These results support the hypothesis that C/EBP $\beta$ is involved in folliculogenesis and ovulation. However, CITED4 functions in cell proliferation, apoptosis, and steroidogenesis in pre-ovulatory GCs remain unexamined.

To provide insights into the role of CITED4 in regulating follicular development in $\mathrm{Hu}$ sheep, the present study aimed to detect the expression of CITED4, $\mathrm{CBP}, \mathrm{C} / \mathrm{EBP} \alpha$, and $\mathrm{C} / \mathrm{EBP} \beta$ in ovaries and investigate the role of CITED4 in GC proliferation, apoptosis, and steroidogenesis. Additionally, we investigated whether direct ERK1/2 inhibition could block CITED4 and $\mathrm{LH}$-target gene expression in the GCs of Hu sheep.

\section{Materials and methods}

\section{Ethics and reagents}

All experimental procedures, including animal care, were approved by the Institutional Animal Care and Use Committee of Nanjing Agricultural University. All reagents used in this study were purchased from Life Technologies, unless otherwise mentioned. All antibodies were purchased from commercial suppliers (Table 1).

\section{Sample collection}

During the breeding season (from October to January), $\mathrm{Hu}$ sheep ovaries were collected from a local abattoir (Taicang, Jiangsu; $121^{\circ} 10^{\prime} \mathrm{E}, 31^{\circ} 45^{\prime} \mathrm{N}$ ), immediately immersed in sterilized physiological saline (supplemented with 100 IU/L penicillin and $50 \mathrm{mg} / \mathrm{L}$ streptomycin; at $30-35^{\circ} \mathrm{C}$ ), and transported within 30 min to the laboratory. After washing five times with physiological saline, the connective tissues were removed from the collected ovaries. For immunohistochemical assay, ten ovaries were randomly selected, fixed in $4 \%$ formaldehyde for $24 \mathrm{~h}$, and embedded in paraffin. Corpora lutea were dissected from ten ovaries, measured with a caliper, and classified into three size ranges (5-6, 7-8 and 9-10 mm diameter). Meanwhile, female reproductive organs (oviduct, ovary, uterine horn, hypothalamus, and pituitary) were collected from five ewes during estrus, at the Jiangyan Experimental Station (Taizhou, Jiangsu Province, China). The aforementioned samples were immediately frozen in liquid nitrogen and stored at $-80^{\circ} \mathrm{C}$.

GCs were isolated according to our previous protocol (Zhang et al. 2016). Briefly, follicular fluid was aspirated from healthy follicles (2-5 mm diameter). Subsequently, GCs were pelleted by centrifugation at $1000 \times \mathbf{g}$ for $5 \mathrm{~min}$ and resuspended in red blood cell lysis buffer for 1 min. After washing with Dulbecco's PBS, the cell pellets were resuspended in $0.3 \%$ hyaluronidase for $90 \mathrm{~s}$. Finally, the GCs were resuspended in culture medium (DMEM/nutrient mixture F-12 (DMEM/F12) supplemented with $10 \%$ fetal bovine serum (FBS), $2 \mathrm{mM}$ L-glutamine, 100 $\mathrm{IU} / \mathrm{mL}$ penicillin, and $100 \mu \mathrm{g} / \mathrm{mL}$ streptomycin) at $37^{\circ} \mathrm{C}$ in a humidified atmosphere containing $5 \% \mathrm{CO}_{2}$. Notably, after 24-48 h of culture with serum, most GCs were converted into luteinized GCs (Tosca et al. 2010).

\section{Cloning of CITED4 in Hu sheep}

To obtain the coding DNA sequence region of the CITED4 gene, specific primers with an amplicon of 989 bp were designed using the Primer 5.0 software and are listed in Table 2. RNA isolated from Hu sheep ovaries was transcribed into cDNA and amplified using RT-PCR based on our previous protocol (Yao et al. 2017a). Briefly, the following parameters were used: $98^{\circ} \mathrm{C}$ for $3 \mathrm{~min} ; 35$ cycles at $98^{\circ} \mathrm{C}$ for $10 \mathrm{~s}, 60^{\circ} \mathrm{C}$ for $30 \mathrm{~s}$, and $72^{\circ} \mathrm{C}$ for $90 \mathrm{~s}$ or $45 \mathrm{~s}$; and then a final extension

Table 1 Details of antibodies used.

\begin{tabular}{lllll}
\hline Antibodies & Cat No. & Source & Dilution of IHC & Dilution of WB \\
\hline CITED4 & ab134072 & Abcam, Cambridge, MA, USA & $1: 100$ & $1: 1000$ \\
CBP & AF0139 & Affinity Biosciences, Cincinnati, USA & $1: 100$ & - \\
C/EBP $\alpha$ & A0904 & ABclonal, Wuhan, China & $1: 100$ & - \\
C/EBP $\beta$ & A0711 & ABclonal, Wuhan, China & $1: 100$ & $1: 500$ \\
ERK1/2 & AF1051 & Beyotime, Shanghai, China & - & $1: 1000$ \\
p-ERK1/2 & AF1891 & Beyotime, Shanghai, China & - & $1: 1000$ \\
PCNA & Ab15497 & Abcam, Cambridge, MA, USA & - & $1: 1000$ \\
BAX & $50599-2-$ Ig & ProteinTech, Chicago, IL, USA & - & $1: 2000$ \\
$\beta$-actin & bs-0061R & Bioss, Beijing, China & - & $1: 2000$ \\
GAPDH & $60004-1-$ Ig & ProteinTech, Chicago, IL, USA & - & $1: 2000$ \\
Goat anti-Rabbit lgG & SA00001-2 & ProteinTech, Chicago, IL, USA & $1: 100$ & $1: 2000$ \\
\hline
\end{tabular}

Cat No., category number; IHC, immunohistochemistry; WB, western blot. 
Table 2 Primer sequences used for this study.

\begin{tabular}{|c|c|c|c|c|c|}
\hline \multirow[t]{2}{*}{ Items } & \multicolumn{2}{|c|}{ Primer sequence $\left(5^{\prime}-3^{\prime}\right)$} & \multirow[t]{2}{*}{$\begin{array}{l}\text { Fragment } \\
\text { Size (bp) }\end{array}$} & \multirow[t]{2}{*}{ Genebank No. } & \multirow[t]{2}{*}{ Purpose } \\
\hline & Forward & Reverse & & & \\
\hline CITED4 & TTCTGTGTATACTGGGCTGCG & GGAGTCCGAAAAGGGGGTTC & 989 & XM_004003498.4 & RT-PCR \\
\hline CITED4 & ATGGACGCCGAACTCATCG & CCCAAGTCCGAGAAGCAGTC & 128 & XM_004003498.4 & qRT-PCR \\
\hline AREG & CGCCATGACCTTCACAGCTA & CCTTCAGTTACGCTACGGCA & 143 & XM_012180164.3 & qRT-PCR \\
\hline EREG & TGGTGTCCGGTGTGAACATT & GGATCCССTGAGGTCACTCT & 195 & XM_027971077.1 & qRT-PCR \\
\hline PTGS2 & CCAGCCGCAGTAGAGAAAGT & AATGGTGCTCCGGCTTCTAC & 266 & NM_001009432.1 & qRT-PCR \\
\hline PTX3 & TGGTCGCTGATGCTGTGATT & ССАССАССТАСGССАТТСТТ & 193 & XM_004003220.4 & qRT-PCR \\
\hline TNFAIP6 & AGGGCAGAGTTGGATACCCT & ACСАССАСАСТССТТТGСАТ & 146 & XM_004004704.3 & qRT-PCR \\
\hline HAS2 & GGAGACATATCGCTGCTGCT & GGCAAAACACTGTTAGGCGG & 184 & XM_004011666.3 & qRT-PCR \\
\hline StAR & GGGCATCCTCAAAGACCAG & TCСАССАССАССТССААС & 120 & NM_001009243.1 & qRT-PCR \\
\hline $3 \beta-H S D$ & ATCCACACCAGCACCATAG & TTCCAGCACAGССТTCTC & 144 & NM_001135932.1 & qRT-PCR \\
\hline Caspase3 & GGCTCTGAGTGTTTGGGGAA & ССTGGACAAAGTTCCGTGGT & 131 & XM_027962551.1 & qRT-PCR \\
\hline Caspase8 & TGAAGGTTCCAGGATTCGCC & GGCTTAGGAACTTGAGGGCA & 136 & XM_012142484.3 & qRT-PCR \\
\hline BAX & CGAGTGGCGGCTGAAAT & GGTCTGCCATGTGGGTGTC & 286 & XM_027978594.1 & qRT-PCR \\
\hline Bcl-2 & CGCATCGTGGCCTTCTTT & CGGTTCAGGTACTCGGTCATC & 113 & XM_027960877.1 & qRT-PCR \\
\hline CyclinD1 & ACATGGAGCTGGTCCTGGTGA & GGAGGGTGGGTTGGAAATGAA & 188 & XM_027959928.1 & qRT-PCR \\
\hline CDK4 & CAGTGGCTGAGATTGGTGTCG & АССТСССGAACGGTGСТGAT & 148 & XM_012158548.3 & qRT-PCR \\
\hline CDK1 & ATGGCTTGGATCTGCTCTCG & TGCTCTTGACACAACACAGGA & 154 & NM_001142508.1 & qRT-PCR \\
\hline CyclinB1 & GCTTGGAGACATCGGTAACA & GGAGCCTTTTCCAGAGGTTTTG & 129 & XM_004016916.3 & qRT-PCR \\
\hline GAPDH & GTCAAGGCAGAGAACGGGAA & GGTTCACGCCCATCACAAAC & 232 & XM_012166462.1 & qRT-PCR \\
\hline
\end{tabular}

at $72^{\circ} \mathrm{C}$ for $6 \mathrm{~min}$. After gel electrophoresis, PCR products of the correct size were cloned into a pMD19-T vector (6013; Takara, Dalian, China). Cloned vectors were transformed into Escherichia coli DH5a cells (9057; Takara) using standard procedure. After sequencing, the amino acid sequence was predicted using BLAST and aligned with sequences from other species using the DNAMAN software. The sequence of CITED4 from Hu sheep was submitted to NCBI under the accession number MT940221.

\section{In vitro experiments examining $\mathrm{Hu}$ sheep GCs}

GCs were cultured with DMEM/F12 in six-well plates at a density of $5 \times 10^{5}$ cells/well. After overnight culture (at $60-70 \%$ confluence), the medium was replaced with serumfree DMEM/F12 with the following treatments: (1) medium containing various concentrations of $\mathrm{LH}(0,1,2,5,10 \mathrm{IU} /$ $\mathrm{mL}$; Sansheng, Ningbo, China) for 4 h; (2) medium containing $\mathrm{LH}(5 \mathrm{IU} / \mathrm{mL})$ at the indicated time points; (3) medium with or without $\mathrm{LH}(5 \mathrm{IU} / \mathrm{mL})$ and $U 0126(20 \mu \mathrm{M})$ for $4 \mathrm{~h}$. (4) medium with or without prostaglandin (PGE2, P0409; Sigma-Aldrich, Inc.; $500 \mathrm{ng} / \mathrm{mL}$ ) and U0126 (S1102; Selleck, Houston, TX, USA; $20 \mu \mathrm{M}$ ) for $4 \mathrm{~h}$. After incubation at $37^{\circ} \mathrm{C}$ in a humidified atmosphere with $5 \% \mathrm{CO}_{2}$, the cells were collected for further analyses.

CITED4 overexpression and knockdown were achieved using the pEX-4-CITED4 plasmid and siRNA, respectively, as well as the negative controls ( $\mathrm{pEX}-4-\mathrm{NC}$ and siRNA-NC), which were synthesized by GenePharma (Shanghai, China). All siRNA sequences are listed in Table 3. GCs cultured to $60-70 \%$ confluence were transfected with pEX-4-CITED4 plasmid or siRNA, using Lipofectamine 3000, according to the manufacturer's instructions. After $48 \mathrm{~h}$, the transfected cells were collected for subsequent analyses. The medium samples were also obtained to evaluate $\mathrm{E}_{2}$ and $\mathrm{P}_{4}$ levels using ELISA kits (JEB-14992-1 and JEB-15484-1, respectively; Jin Yibai Biological Technology, Nanjing, China).

When GCs attained $60-70 \%$ confluence, pEX-4-NC and pEX-4-CITED4 plasmids as well as siRNA-NC and siRNACITED4 were transfected into GCs for $24 \mathrm{~h}$. Subsequently, the medium was replaced with serum-free DMEM/F12 in the absence or presence of $\mathrm{LH}(5 \mathrm{IU} / \mathrm{mL})$ or PGE2 $(500 \mathrm{ng} / \mathrm{mL})$ for $4 \mathrm{~h}$. GCs were then collected for gene expression assays.

\section{Cell proliferation analysis}

Proliferation of the transfected GCs was measured with the CCK-8 assay (Cell Counting Kit-8; KGA317; KeyGen, Nanjing, China) and EdU incorporation assay (5-ethynyl2'-deoxyuridine; KGA337-500; KeyGen, Nanjing, China), according to the manufacturer's instructions. Briefly, the transfected GCs were treated with the CCK-8 reagent $(10 \mu \mathrm{L} /$ well) and incubated for $2 \mathrm{~h}$ at $37^{\circ} \mathrm{C}$. The optical density was measured at $450 \mathrm{~nm}$ using a spectrophotometer (Thermo Fisher Scientific Inc.). For EdU analysis, five areas were selected from each replicate. Fixed and stained cells were visualized with

Table 3 The siRNA sequences of CITED4 and the normal control.

\begin{tabular}{lll}
\hline Items & \multicolumn{1}{c}{ Primer sequence $\left(5^{\prime}-3^{\prime}\right)$} & \\
\hline siRNA-NC & Sense & Antisense \\
siRNA-CITED4 & UUCUCCGAACGUGUCACGUTT & ACGUGACACGUUCGGAGAATT \\
\hline
\end{tabular}


an LSM710 laser scanning confocal microscope (Carl Zeiss), based on our previous protocol (Yao et al. 2020), and counted using Image J software (NIH).

\section{Apoptosis and cell cycle analysis}

Apoptosis and cell cycles were analyzed by flow cytometry (BD Biosciences) using an Annexin V-APC/7-ADD apoptosis detection kit (KGA1025; KeyGen, Nanjing, China) and propidium iodide (PI; 550825; BD Pharmingen, San Diego, CA, USA), respectively. All procedures were conducted according to the manufacturer's instructions.

\section{Immunohistochemistry}

Immunohistochemistry was performed on Hu sheep ovaries, based on our previous protocol (Yao et al. 2017a). Rabbit anti-CITED4, -CBP, -C/EBP $\alpha$, and -C/EBP $\beta$ were used as primary antibodies, and goat anti-rabbit IgG was used as the secondary antibody. The negative controls were incubated with Tris-buffered saline instead of primary antibodies. All sections were stained with diaminobenzidine (DAB; AR1026; Boster, Wuhan, China) and examined with a light microscope (Nikon).

\section{Quantitative reverse transcription-polymerase chain reaction ( $q R T-P C R)$ analysis}

Total RNA was extracted using TRIzol reagent (Invitrogen), following the manufacturer's instructions. Subsequently, cDNA was synthesized using the PrimeScript RT reagent kit with gDNA Eraser (RR047A; Takara). Then, qRT-PCR was performed with SYBR Green Master Mix (Q711-02; Vazyme, Nanjing, China) using the ABI 7500 Real-Time PCR System (Applied BioSystems), following the manufacturer's protocol. Relative gene expression levels were quantified using the $2^{-}$ $\triangle \triangle \mathrm{CT}$ method. GAPDH was used as an internal control. Primers are listed in Table 2.

\section{Western blot analysis}

To detect protein expression, western blot was performed based on our previous protocol with a minor modification (Yao et al. 2017a). Briefly, the total protein was extracted using cell protein extraction reagent containing phenylmethanesulfonyl fluoride and phosphatase inhibitors. Protein concentrations were determined with a BCA protein assay kit (P0010; Beyotime, Shanghai, China). For each replicate, $15 \mu \mathrm{g}$ of total protein was separated on a 10\% SDS-PAGE and transferred onto a polyvinylidene fluoride membrane. Subsequently, the membranes were blocked with $5 \%$ fat-free milk for $2 \mathrm{~h}$ at room temperature (RT) and incubated at $4{ }^{\circ} \mathrm{C}$ overnight with primary antibodies (rabbit anti-CITED4, -C/EBP $\beta$, -PCNA, -BAX, -GAPDH and - $\beta$-actin). After washing with Tris buffer solution containing $0.05 \%$ Tween 20 , the membranes were incubated with the secondary antibody at RT for $1 \mathrm{~h}$. The immunoreactions were visualized with an ECL detection system (Fujifilm, Tokyo, Japan). The chemiluminescence intensity of protein bands was quantified with the Image J software. Of note, the C/EBP $\beta$ antibody was a polyclonal antibody that recognized both long and short isoforms of C/EBP $\beta$.

\section{Statistical analysis}

Each experiment included three independent samples, and was repeated three times. Statistical analyses were performed with SPSS (version 19.0 for Windows). Differences between groups were statistically analyzed using one-way ANOVA followed by Tukey's post hoc test. Data are expressed as mean \pm S.E.M. $P$-values $<0.05$ were considered significant.

\section{Results \\ cDNA cloning and sequence analysis of the CITED4 gene}

Sequence analysis of the cDNA fragment (989 bp) demonstrated that CITED4 coding sequence comprised $558 \mathrm{bp}$ and encoded a 185-amino acid protein (Fig. 1A).
A

1 TTCTG TG IATACTGGGCTGCGCAGGAMCCAGGGCCGGCCTCGGTTTTCCCITGCCCGGOC

61 GGGCTGCOGAGAGAGCACGAGGCTCG TATCGCTCGCCGCAGAGGAACAGCTGGCCGGGAT

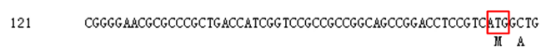

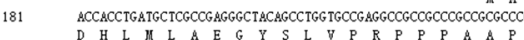

241 CCCACGGCCCTCAGGOGCTCCGGACGCTGCAGCCGTACTCGAGCCCAGGCCTGGACAGCC

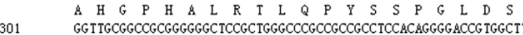
GGTTGCGGCCGCGGGGGCTCCGCTGGGCCCGCCGCCGCCTCCACAGGGGACCG TGGCTT
$G$ L R P R R A A P A P P P P P Q G T V A ACGGGGCCTICGGGCOG ICGCCCACCTTCCAGCOCITCCCGGCTGTGCCACCGCOCGCG A G I A H L Q P F A T L Y P G R A S M P

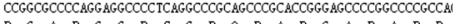

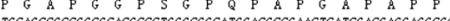
$L Q P$ P A H A L G G IIDAE A L I D E E A TGACG TCGCTGGAGCTGGAGCTCGGGCTGCACCGCG TGCGCGATCTGCCCGAGCTCITOC

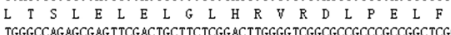

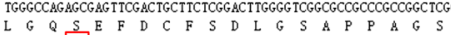

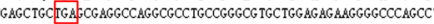

CGCGG ITAGTGCACCGAGCCGACGCCGGCCTGGGACGCCTGGCCTCACTCCAGGCCCTGC

CTCCTGCAGGSTGACABTTTGAGTTCATCTCTCTGACCCGGAGCCTCAGCGG TARAATGB

AGGGGGAMGGAHCOCOCTITTCGGACTOC

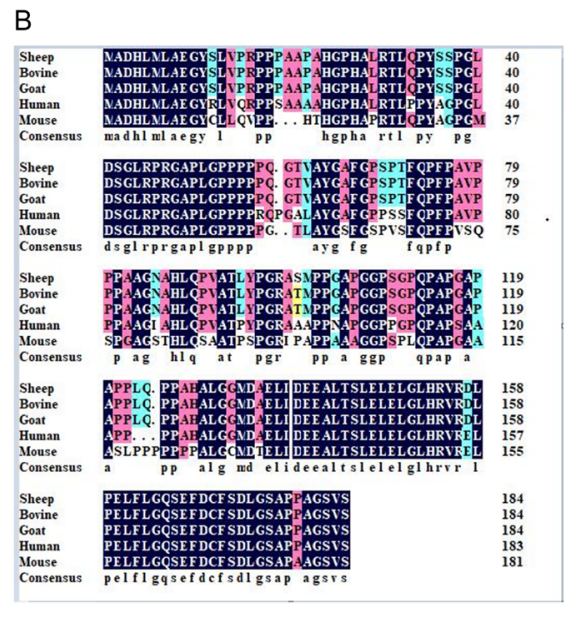

Reproduction (2021) 161 255-267
Figure 1 Characterization of CITED4 sequences in Hu sheep. (A) Partial nucleotide and predicted amino acid sequences of CITED4 in Hu sheep. The start and stop codons are shown in the red box. The amino acid sequence was predicted using BLAST and is presented under the nucleotide coding sequence. (B) Comparison of sheep CITED4 amino acid sequence with bovine, goat, human, and mouse sequences. The sequences were aligned using the DNAMAN software. 
As shown in Fig. 1B, alignment of the predicted protein with homologous proteins from other species demonstrated high homology with goat $(98.40 \%)$, bovine $(98.40 \%)$, and human $(86.10 \%)$ sequences and moderate sequence identity with mouse sequences $(72.19 \%)$.

\section{CITED4/CBP pathway proteins are primarily present in ovarian GCs and in corpora lutea of Hu sheep}

To understand the role of CITED4/CBP pathway proteins in the ovary of Hu sheep, immunohistochemistry was performed. As shown in Fig. 2A, CITED4 (a, b), CBP (d), C/EBP $\alpha(\mathrm{g}, \mathrm{h})$, and C/EBP $\beta(\mathrm{k}, \mathrm{l})$ were predominantly present in GCs of antral follicles; meanwhile, C/EBP $\alpha$ (f) and C/EBP $\beta$ (g) were observed following the primordial follicle stage. Positive signals for CITED4 (c), CBP (e), C/
$\mathrm{EBP} \alpha(\mathrm{i})$, and $\mathrm{C} / \mathrm{EBP} \beta(\mathrm{m})$ were also detected in the luteal cells. No positive signals were observed in the negative controls $(\mathrm{n}-\mathrm{q})$. CITED4 mRNA expression was higher in the ovaries and corpora lutea than in the hypothalamus, pituitary glands, uterine horn, and oviducts (Fig. 2B). The highest expression of CITED4 mRNA was detected in 7-8 $\mathrm{mm}$ corpora lutea, while the lowest expression was observed in 5-6 mm corpora lutea (Fig. 2C).

\section{CITED4 is a downstream target of the ERK1/2 pathway in Hu sheep GCs}

Next, we used Hu sheep GCs as a model to evaluate the effect of LH on CITED4 expression. Results showed that CITED4 mRNA expression increased with increasing LH concentrations in culture medium (Fig. 3A; $P<0.05$ ).
A
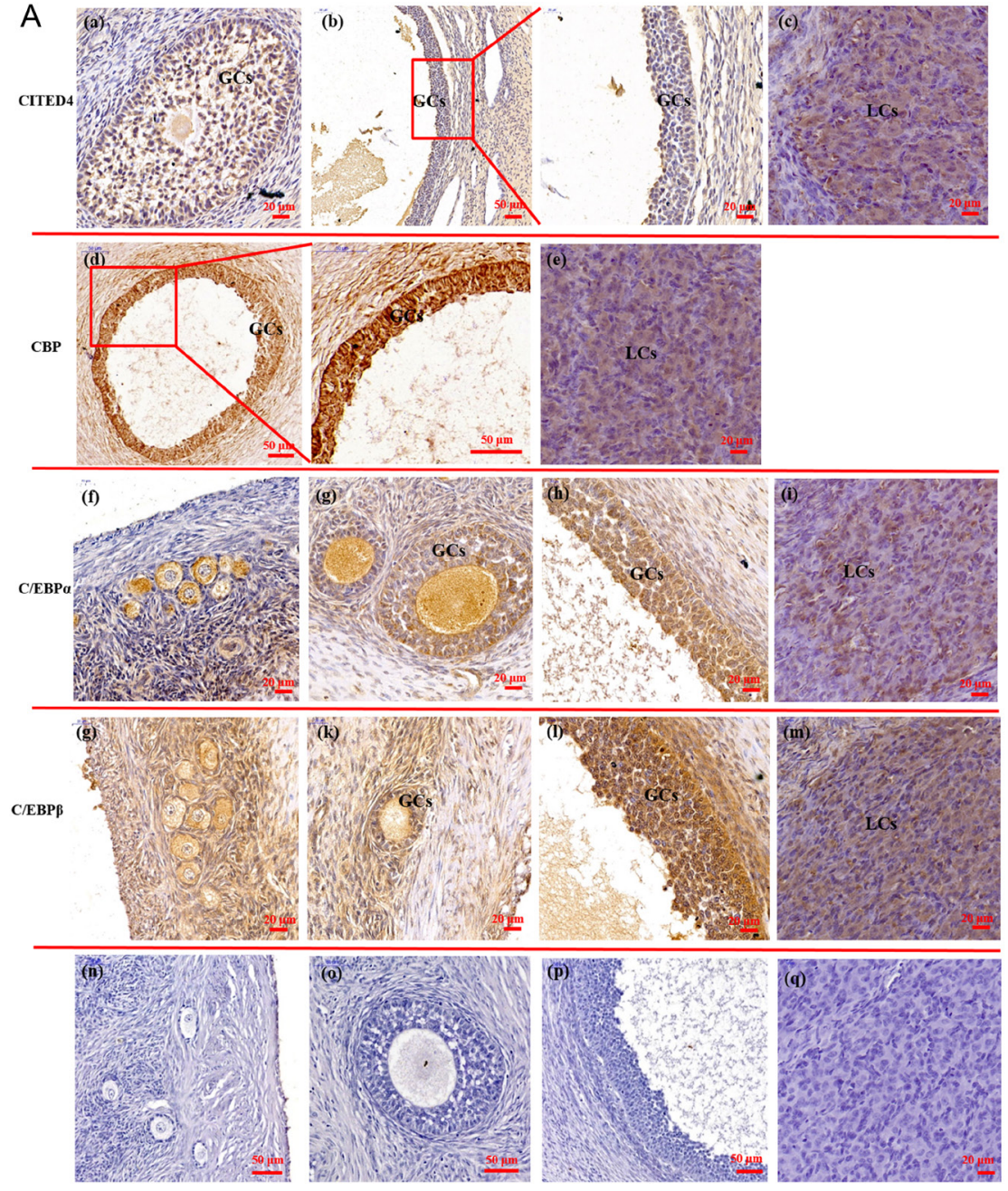
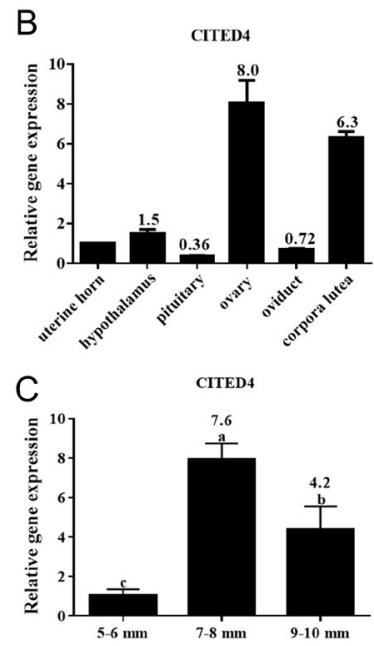

Figure 2 CITED4/CBP pathway proteins are primarily present in Hu sheep GCs. (A) Localization of CITED4 (a-C), CBP (d and e), C/EBP $\alpha(f-i)$, and C/EBP $\beta(\mathrm{g}-\mathrm{m})$ in Hu sheep ovaries was detected by immunohistochemistry. Negative control $(\mathrm{n}-\mathrm{q})$. All sections were stained with DAB. Scale bars: $20 \mu \mathrm{m}$ or $50 \mu \mathrm{m}$. GCs, granulosa cells; LCs, luteal cells. (B and C) CITED4 mRNA expression in Hu sheep female reproductive organs (B) and corpora lutea of various sizes (C) was analyzed with qRT-PCR. Data are presented as mean \pm S.E.M., and different superscript letters $(\mathrm{a}-\mathrm{c})$ represent significant differences $(P<0.05)$. The ratio above each column represents the mean mRNA expression levels of CITED4 between experiment and control groups. Each experiment included three independent samples and was repeated three times. 

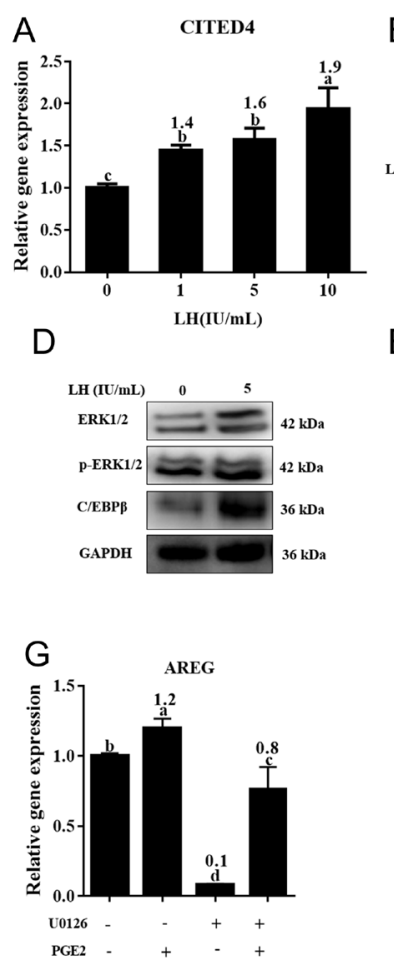

B

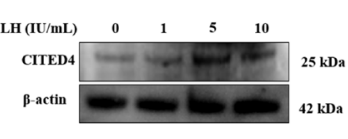

E

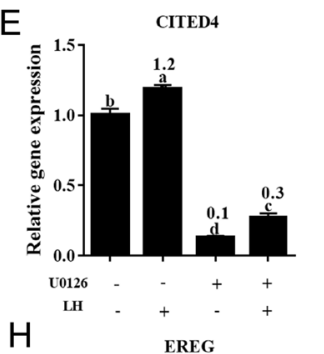

$\mathrm{H}$

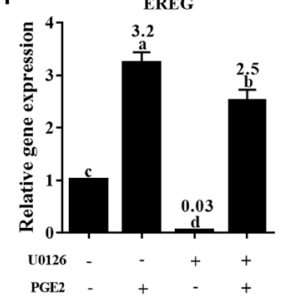

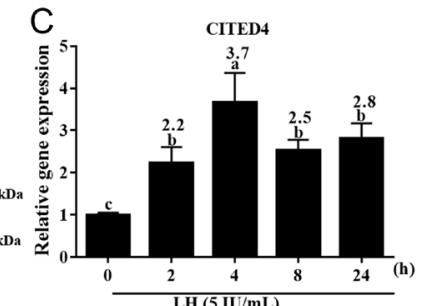

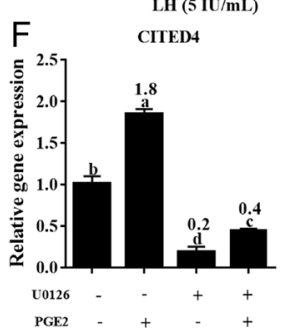

Figure 3 CITED4 is a downstream target of the ERK1/2 pathway in Hu sheep GCs. (A) qRT-PCR and (B) Western blot results evaluating CITED4 expression in GCs after treatment with various $\mathrm{LH}$ concentrations for 4 h. (C) qRT-PCR results of CITED4 mRNA expression in GCs at different intervals after $\mathrm{LH}(5 \mathrm{IU} / \mathrm{mL})$ treatment. (D) Western blot results for ERK1/2, p-ERK1/2, and C/EBP $\beta$ protein expression in GCs after $\mathrm{LH}$ treatment for $4 \mathrm{~h}$. (E) qRT-PCR results for CITED4 mRNA expression in GCs with or without the administration of LH $(5 \mathrm{IU} / \mathrm{mL})$ and U0126 (20 $\mu \mathrm{M})$ for $4 \mathrm{~h}$. (F, G and H) qRT-PCR results for CITED4, AREG, and EREG mRNA expression in GCs with or without the administration of prostaglandin (PGE2, $500 \mathrm{ng} / \mathrm{mL}$ ) and $U 0126$ $(20 \mu \mathrm{M})$ for $4 \mathrm{~h}$. Data are presented as mean \pm S.E.M., and different superscript letters $(\mathrm{a}-\mathrm{d})$ represent significant differences $(P<0.05)$. The ratio above each column represents the mean mRNA or protein expression levels of genes between experiment and control groups. Each experiment included three independent samples and was repeated three times.

This association was also confirmed at the protein level (Fig. 3B). CITED4 mRNA expression increased remarkably from 2-24 h after $\mathrm{LH}$ treatment, compared with that in the untreated controls (Fig. 3C; $P<0.05$ ); the maximum increase in expression was reached 4 $\mathrm{h}$ after $\mathrm{LH}$ treatment. $\mathrm{LH}$ treatment also increased the protein expression of ERK1/2, p-ERK1/2, and C/EBP $\beta$ in GCs (Fig. 3D).

We further investigated whether direct inhibition of ERK1/2 using U0126 could block CITED4 and LH-target genes expression in GCs. Notably, U0126 significantly inhibited CITED4 mRNA expression, which was attenuated by $\mathrm{LH}$ (Fig. $3 \mathrm{E} ; P<0.05$ ). Meanwhile, PGE2, the physiological intra-follicular mediator of LH effects, induced CITED4 mRNA expression in the GCs. However, its effects were blocked by U0126 (Fig. 3F; $P<0.05)$. U0126 also significantly weakened PGE2 influence on AREG and EREG mRNA expression (Fig. 3G and $\mathrm{H} ; P<0.05)$.

\section{CITED4 is required for $\mathrm{LH}$-target gene expression in GCS}

The pEX-4-CITED4 plasmid was constructed by cloning CITED4 into the pEX-4 vector (Fig. 4A, B and C). CITED4 mRNA and protein levels were enhanced by CITED4 overexpression and were attenuated by CITED4 knockdown (Fig. 4D, E, F and G; $P<0.05$ ).

Next, we investigated whether CITED4 is required for LH-triggered target gene expression in Hu sheep GCs. As shown in Fig. 5A, B, C, D, E, F, G, H, I, J, K, $\mathrm{L}, \mathrm{M}$ and $\mathrm{N}$, with the exception of the HAS2 and PTX3 genes $(P>0.05)$, addition of $\mathrm{LH}$ to the culture media significantly enhanced the mRNA expression of CITED4 and ovulation-related genes (EREG, AREG, PTGS2, and TNFAIP6) in GCs, which are considered LH-target genes $(P<0.05)$. Meanwhile, with the exception of TNFAIP6 $(P>0.05)$, mRNA expression of LH-target genes was upregulated by CITED4 overexpression and downregulated by CITED4 knockdown $(P<0.05)$. Moreover, CITED4 overexpression moderately increased $\mathrm{GC}$ responses to $\mathrm{LH}$ by significantly increasing $\mathrm{LH}$-target gene mRNA expression, whereas the opposite changes were observed with CITED4 knockdown $(P<0.05)$. The mRNA levels of CITED4 and LH-target genes in the GCs (AREG, EREG, HAS2, and TNFAIP6) increased significantly $4 \mathrm{~h}$ after PGE2 treatment (Fig. 5O, P, Q, R and $S ; P<0.05)$. In contrast, knockdown of CITED4 in GCs significantly weakened PGE2-induced LH-target gene expression (Fig. 5O, P, Q, R and S; $P<0.05$ ).

\section{CITED4 effect on Hu sheep GC proliferation}

$\mathrm{EdU}$ and CCK8 assays were conducted to characterize CITED4 effects on the in vitro GC proliferation. CITED4 overexpression and knockdown moderately promoted and inhibited GC proliferation, respectively (Fig. 6A, B and $C ; P<0.05$ ). The cell cycle progression of CITED4overexpressing GCs was in line with its effects on proliferation, as demonstrated by the significant decrease in $S$ phase and increase in $G 2 / M$ phase percentages in transfected GCs (Fig. 6D; $P<0.05$ ). However, no changes in GC cell cycle progression were observed with CITED4 knockdown (Fig. 6E; $P>0.05$ ). CITED4 overexpression 
A

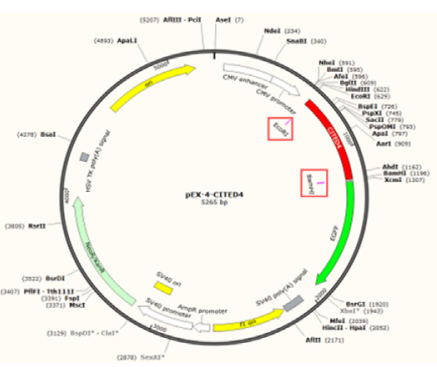

B

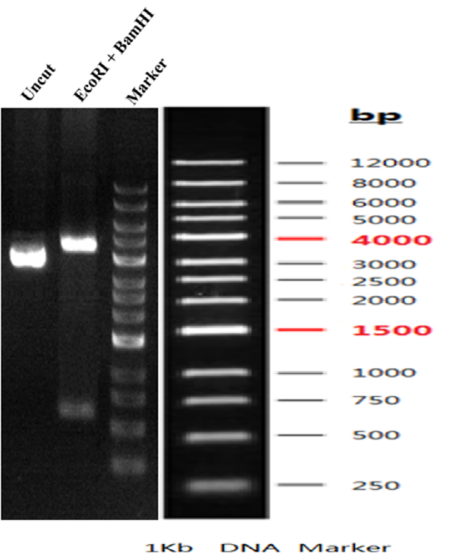

$\mathrm{F}$

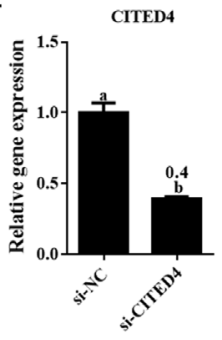

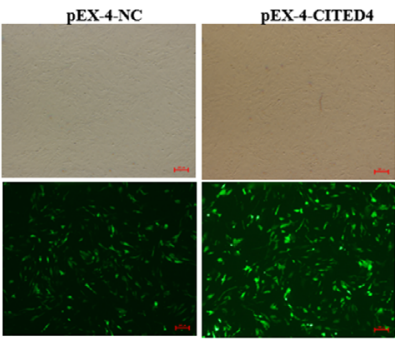

D

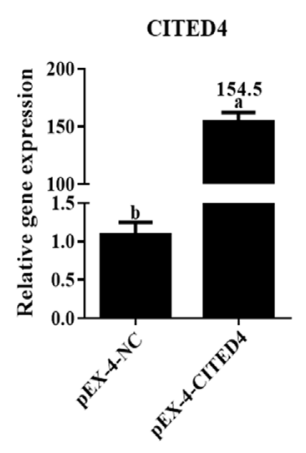

G

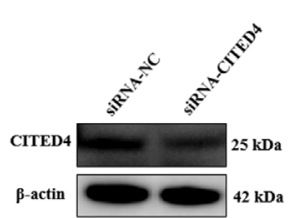

E

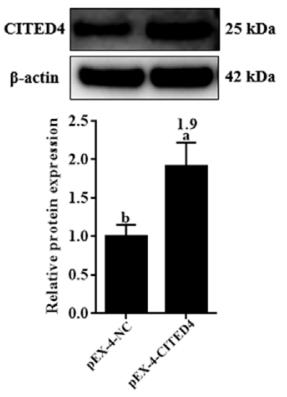

Figure 4 Evaluation of CITED4 overexpression and knockdown efficiency in Hu sheep GCs. (A) The backbone of the CITED4 overexpression vector. (B) Restriction enzyme digestion of the pEX-4-CITED4 plasmid. (C) Representative micrographs of the overexpression vector transfected into $\mathrm{Hu}$ sheep GCs. (D, E, F and G) The efficiency of overexpression ( $\mathrm{D}$ and $\mathrm{E})$ and suppression $(\mathrm{F}$ and G) was determined with qRT-PCR and Western blot. Data are presented as mean \pm S.E.M., and different superscript letters $(a, b)$ represent significant differences $(P<0.05)$. The ratio above each column represents the mean mRNA or protein expression levels of genes between experiment and control groups. Each experiment included three independent samples and was repeated three times.

significantly upregulated CDK1 and Cyclin B1 mRNA expression in the GCs (Fig. 6F; $P<0.05$ ), while CITED4 knockdown significantly downregulated the CDK1 mRNA expression (Fig. 6G; $P<0.05$ ). However, transfection with CITED4 did not alter either the mRNA expression of CDK4 or CyclinD1 (Fig. 6F and G; $P>0.05)$. Additionally, proliferating cell nuclear antigen (PCNA) protein expression in the transfected GCs was significantly enhanced by overexpression and inhibited by knockdown of CITED4 (Fig. $6 \mathrm{H} ; P<0.05$ ).

\section{CITED4 effect on Hu sheep GC the apoptosis}

To elucidate CITED4 role in GC apoptosis, flow cytometry, qRT-PCR, and western blot assays were performed. CITED4 overexpression and knockdown moderately inhibited and promoted apoptosis in GCs, respectively (Fig. 7A; $P<0.05$ ). These results are in conjunction with the significant downregulation of BAX mRNA and protein expression following CITED4 overexpression and upregulation of that following CITED4 knockdown in GCs (Fig. 7B, C and D; $P<0.05$ ). As shown in Fig. 


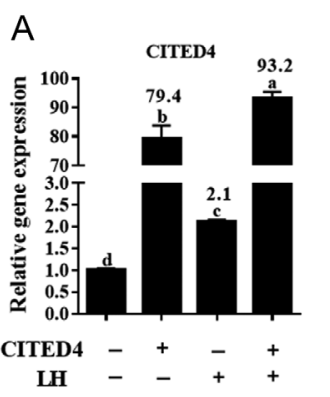

$F \quad$ TNFAIP6
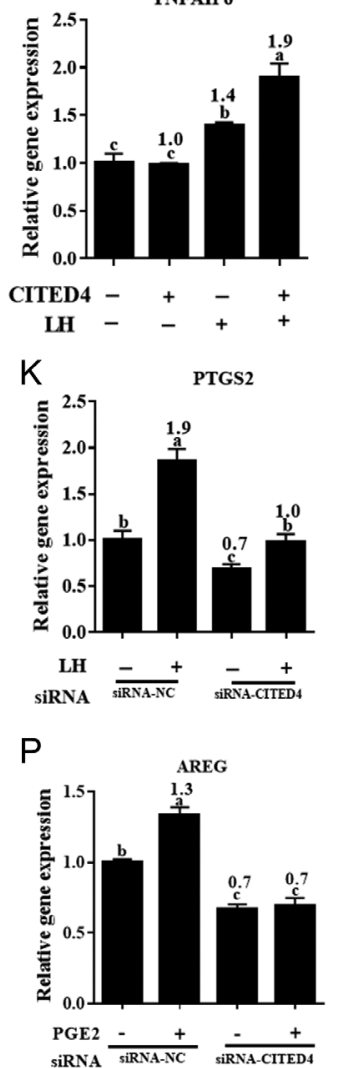

B

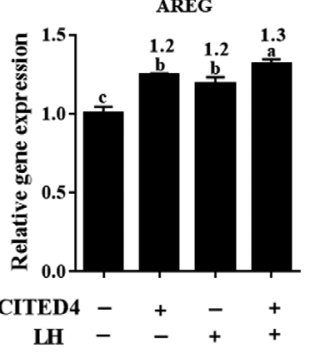

G

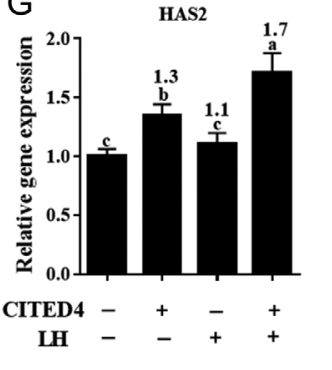

$\mathrm{L}$
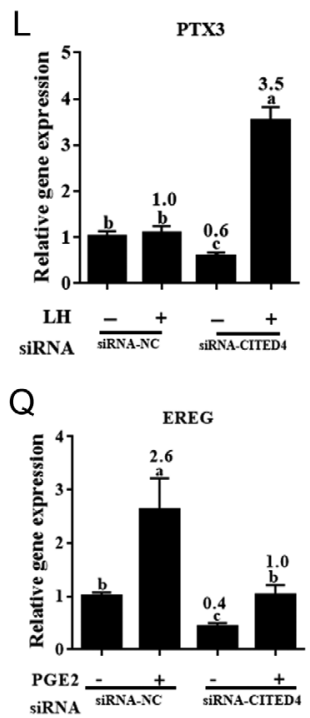

C

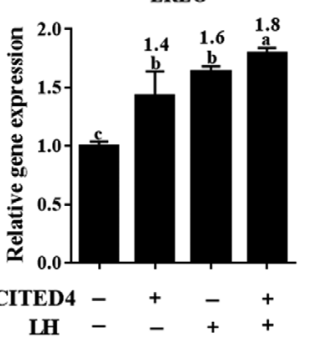

$\mathrm{H}$

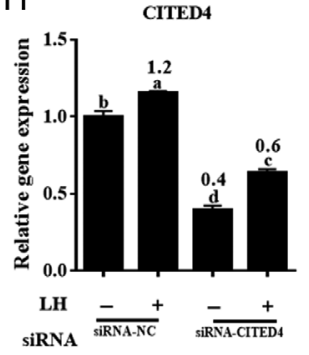

M

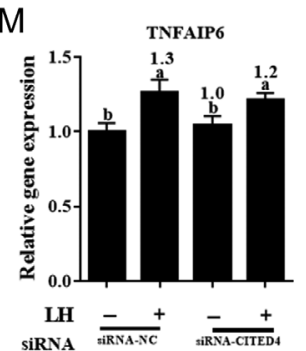

$\mathrm{R}$

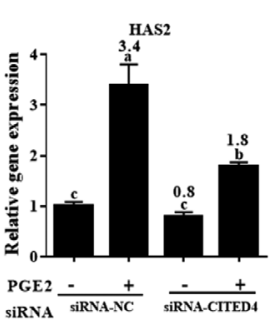

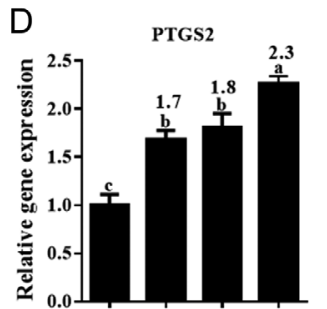
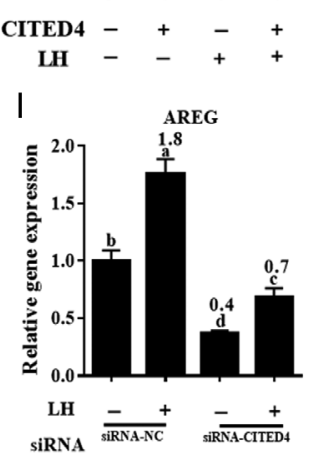

N
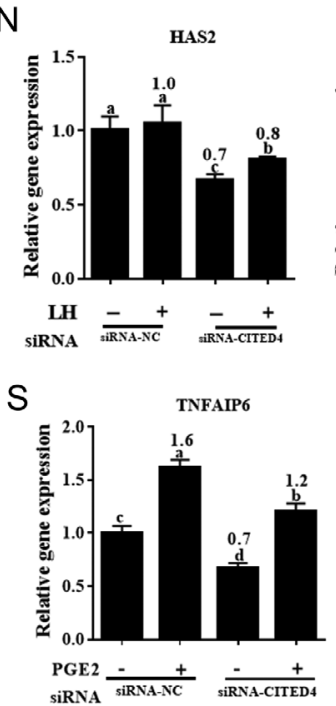
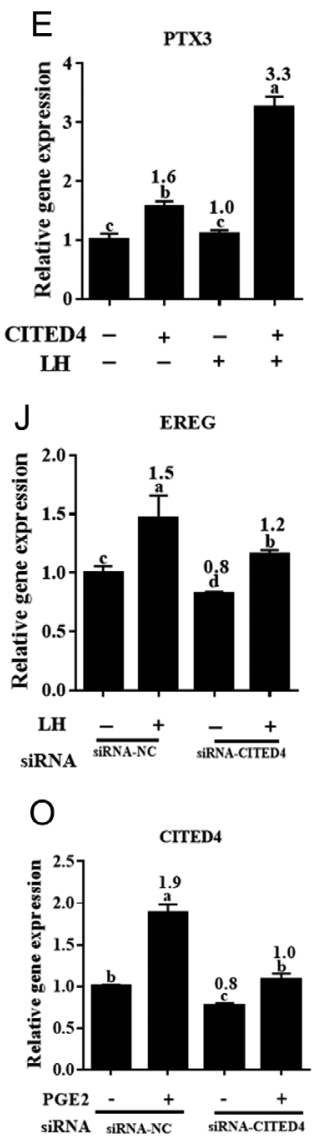

Figure 5 CITED4 is required for LH-target gene expression in GCs. (A, B, C, D, E, F, G, H, I, J, K, L, M and N) qRT-PCR results of mRNA expression of the indicated genes in GCs stimulated with or without $\mathrm{LH}(5 \mathrm{IU} / \mathrm{mL})$ and CITED4 overexpression $(\mathrm{A}, \mathrm{B}, \mathrm{C}, \mathrm{D}, \mathrm{E}, \mathrm{F}, \mathrm{G})$ or knockdown $(\mathrm{H}, \mathrm{I}, \mathrm{J}, \mathrm{K}, \mathrm{L}, \mathrm{M}, \mathrm{N})$. (O, P, Q, R, S) qRT-PCR results for mRNA expression of the indicated genes in GCs stimulated with or without prostaglandin (PGE2, $500 \mathrm{ng} / \mathrm{mL}$ ) and CITED4 knockdown. Data are presented as mean \pm S.E.M., and different superscript letters (a-d) represent significant differences $(P<0.05)$. The ratio above each column represents the mean mRNA expression levels of genes between experiment and control groups. Each experiment included three independent samples and was repeated three times.

mRNA expression (Fig. 8D; $P<0.05$ ); however, no effect on the mRNA expression of $3 \beta-H S D$ was observed (Fig. 8D; $P>0.05)$.

\section{Discussion}

Culturing of GCs remains useful for understanding the molecular processes of follicular development, although suitable in vitro models for exploring ovarian functions are still limited (Skory et al. 2015). Here, we used GCs of antral follicles as a model to elucidate the mechanism through which CITED4 influences Hu sheep GCs; however, the cultured GCs spontaneously convert into luteinized GCs during in vitro culture with serum (Tosca et al. 2010). Although this model may not be ideal for studying the mechanisms involved in follicular development, previous studies (Zhang et al. 2016, 2017, Yao et al. 2017b) have shown that this in vitro culture model can efficiently reflect GCs functions associated with proliferation, apoptosis, and steroidogenesis.

$\mathrm{LH}$ stimulation is critical for the regulation of folliculogenesis and ovulation (Filicori et al. 2002). 
A

D
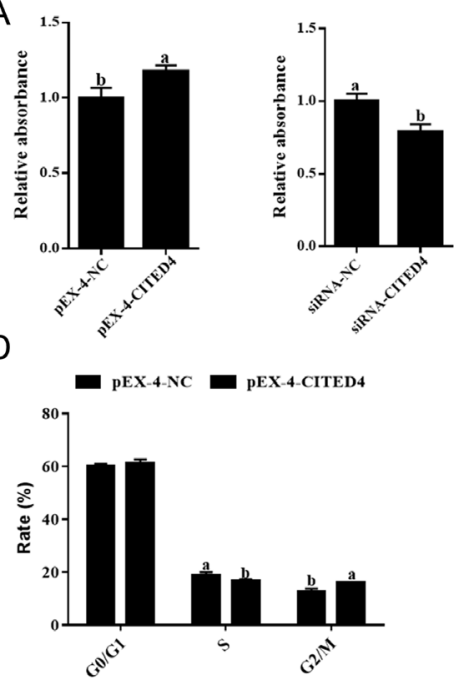

E

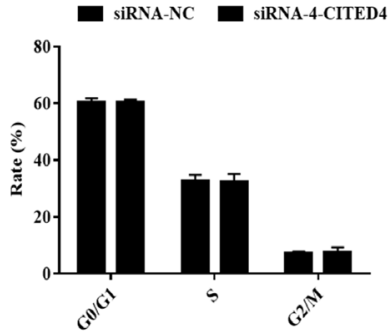

G

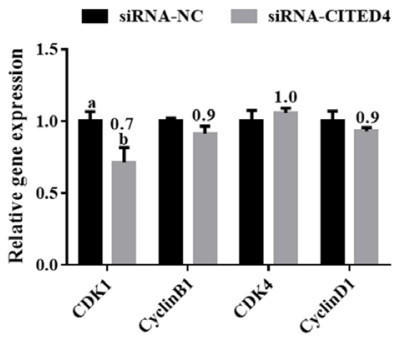

B

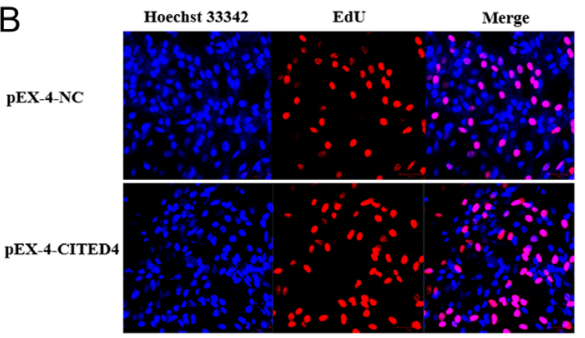

C

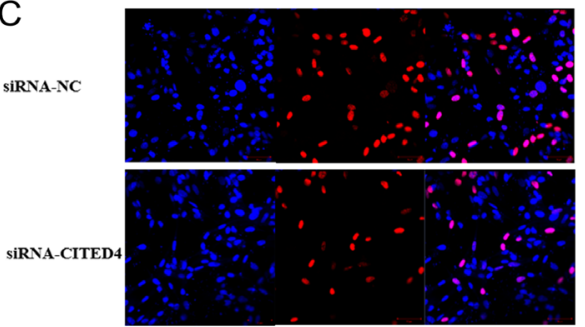

$\mathrm{F}$

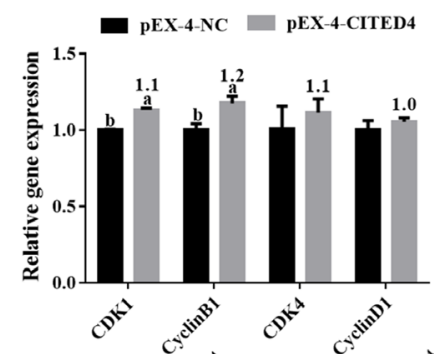

$\mathrm{H}$

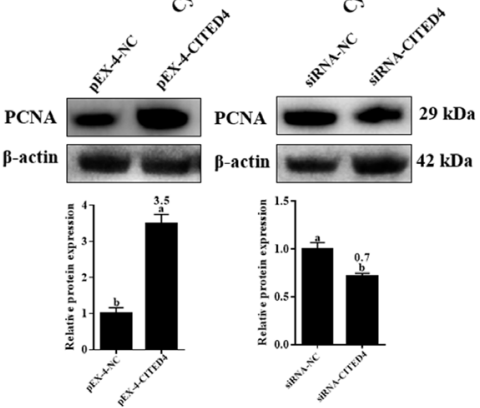

Figure 6 CITED4 regulates cell proliferation in Hu sheep GCs. (A) The percentage of cell viability determined with CCK8 assay. (B and C) Representative micrographs of EdUincorporating cells. Nuclei were stained with Hoechst 33342. (D and E) Histograms represent the percentages of cell cycle distribution. (F and G) Relative expression of cell cycle-associated genes. (H) PCNA protein expression. Data obtained after CITED4 overexpression and knockdown in GCs are presented as mean \pm S.E.M., and different superscript letters $(a, b)$ represent significant differences $(P<0.05)$. The ratio above each column represents the mean mRNA or protein expression levels of genes between experiment and control groups. Each experiment included three independent samples and was repeated three times.
Moreover, during preovulatory follicular growth, $\mathrm{FSH}$ induces the expression of luteinizing hormone receptor (LHR) in GCs, and during advanced follicular development, the stimulation of mature GCs by LH mimics the action of FSH (Palermo 2007). It was suggested that CITED4 could be required for the expression of $\mathrm{LH}$-induced target genes during ovulation in mice (Zhang et al. 2014). Nonetheless, limited information is available regarding CITED4 expression and its roles in sheep ovaries. CITED family proteins may interact with sequence-specific DNA-binding proteins and function as CBP/p300-dependent transcriptional co-activators (Yahata et al. 2002), mediating activities such as the binding of CITED4-CBP with C/EBP $\beta$ to reinforce its transcriptional activity (Lee et al. 2010, Zhang et al. 2014). In this study, CBP, C/EBP $\alpha$, and C/ EBP $\beta$ proteins were mainly present in ovarian GCs of all follicular stages, whereas CITED4 was detected in ovarian GCs of antral follicles. Thus, CBP, C/EBP $\alpha$ and
C/EBP $\beta$ proteins may have critical roles throughout follicular development, although the potential role of CITED4 in GCs in follicular development may start with LHR expression and continue in the corpus luteum influenced by hCG stimulation through LHR (Casarini et al. 2017). This suggestion is consistent with previous studies that indicated high expression levels of CITED4, $\mathrm{CBP}$, and $\mathrm{C} / \mathrm{EBP} \beta$ in mouse ovaries and cultured GCs after hCG treatment (Zhang et al. 2014); similar results were observed for $\mathrm{C} / \mathrm{EBP} \alpha$ and $\mathrm{C} / \mathrm{EBP} \beta$ in porcine GCs after LH or hCG treatment (Zhen et al. 2014).

Although the transfection of CITED4 in mice GCs indicated that CITED4 is indispensable for LH-induced ovulation-related processes (Zhang et al. 2014), no data are available to confirm whether that the expression of LH-triggered target genes is mediated by CITED4 in the GCs of ruminants. Herein, we demonstrated that treatment with LH or PGE2 significantly upregulated the mRNA or protein expression of CITED4 and other 
A
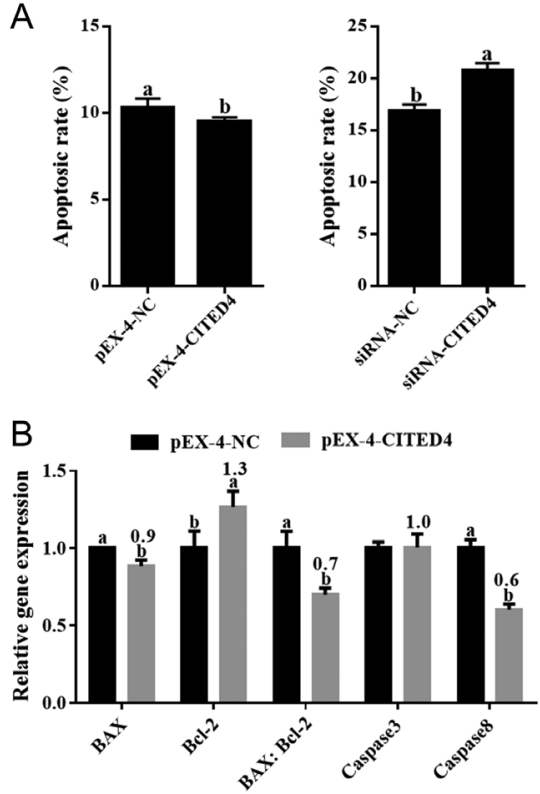

D
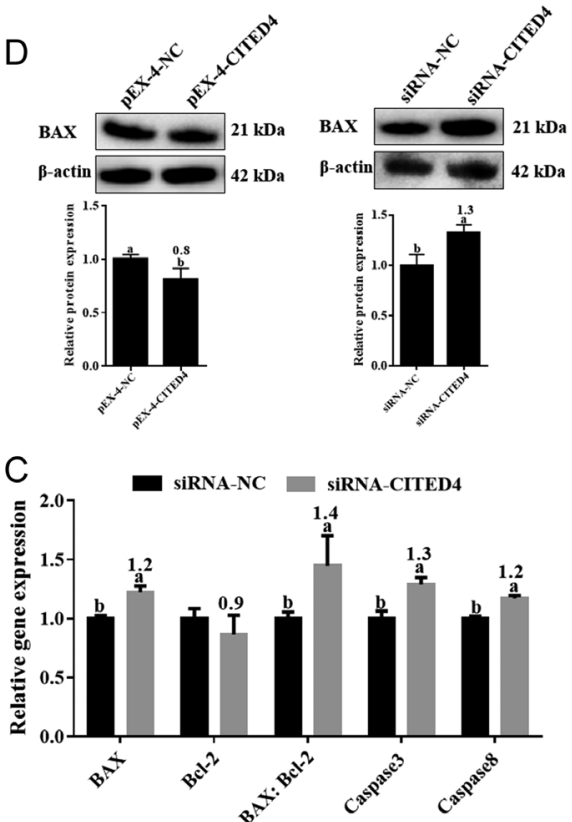

Figure 7 CITED4 regulates cell apoptosis in Hu sheep GCs. (A) Percentage of apoptotic cells. (B and C) Relative expression of apoptosis-related genes. (D) BAX protein expression. Data obtained from CITED4 overexpression and knockdown in GCs are presented as mean \pm S.E.M., and different superscript letters $(a, b)$ represent significant differences $(P<0.05)$. The ratio above the each column represents the mean mRNA or protein expression levels of genes between experiment and control groups. Each experiment included three independent samples and was repeated three times. ovulation-associated genes in GCs, whereas the inhibition of ERK1/2 (U0126) weakened these effects. These findings are consistent with previous studies (Ben-Ami et al. 2006, Yamashita et al. 2007, Fan et al. 2009, Zhang et al. 2014, Tang et al. 2017, Niringiyumukiza et al. 2018). Notably, CITED4 overexpression increased the responses of GCs to $\mathrm{LH}$, whereas the effects of $\mathrm{LH}$ were blocked by silencing CITED4. These observations suggest that CITED4 is crucial for LH-induced ovulation-associated events in sheep. In addition, the ERK1/2 cascade is involved in follicular development and ovulation, as it can mediate $\mathrm{LH}$ actions in rodent GCs during ovulation (Fan et al. 2009) and promote GC proliferation and survival in goats after LH treatment (Gupta et al. 2012). Consistent with this, ERK1/2 and p-ERK1/2 proteins levels in GCs were increased after $\mathrm{LH}$ treatment.

Follicular development is closely related to GC proliferation and apoptosis. The influence of CITED4
A

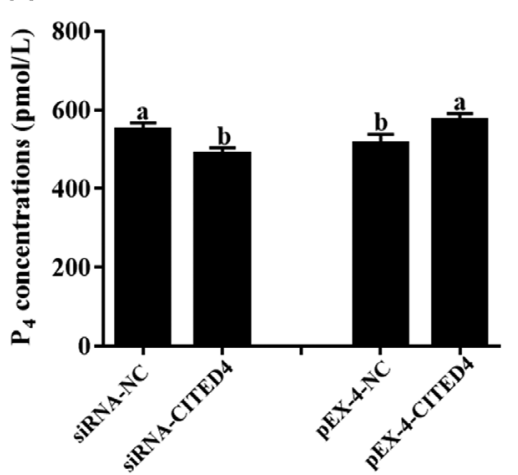

C

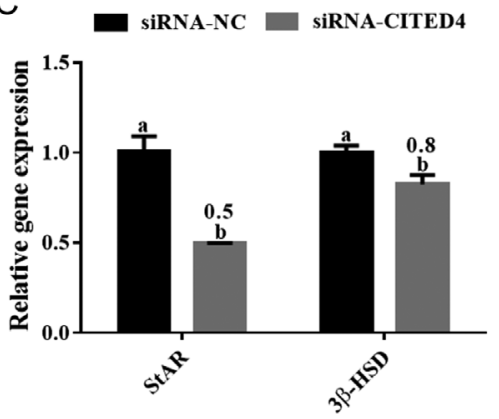

$\mathrm{B}$

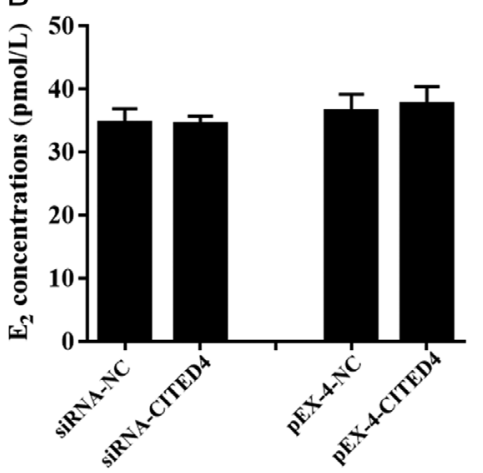

D

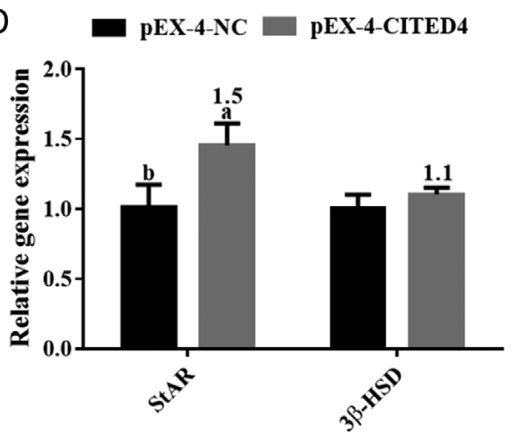

Figure 8 CITED4 regulates $\mathrm{P} 4$ synthesis in $\mathrm{Hu}$ sheep GCs. (A) P4 and (B) E2 levels in the culture medium. (C and D) StAR and 3 $\beta-\mathrm{HSD}$ mRNA expression. Data obtained from CITED4 overexpression and knockdown in GCs are presented as mean \pm S.E.M., and different superscript letters $(a, b)$ represent significant differences $(P<0.05)$. The ratio above each column represents the mean mRNA expression levels of genes between experiment and control groups. Each experiment included three independent samples and was repeated three times. 
on follicular development could be associated with C/ EBP $\beta$, which regulates GC apoptosis and proliferation (Zhen et al. 2014, Yuan et al. 2018), as bonding between CITED4/CBP and C/EBP $\beta$ (as a triple complex) induces the expression of its target genes (Lee et al. 2010, Zhang et al. 2014). In the absence of LH stimulation, our results demonstrated that CITED4 expression is positively correlated with proliferation and negatively correlated with apoptosis of GCs, which could indicate LH-independent responses of CITED4. In addition, previous studies have reported that CITED4 knockdown inhibits the proliferation of colorectal cancer cells (Rogers et al. 2016) and embryonic stem cell derived cardiomyocytes (Miake et al. 2017). However, the inhibition of colorectal cancer cell proliferation following CITED4 knockdown was not found to be associated with induction of apoptosis (Rogers et al. 2016). This discrepancy between the previous results and our study can be attributed to the differences in cell types and transfection conditions. Nevertheless, although the influence of CITED4 on the proliferation and apoptosis of GCs was statistically significant, only slight changes occurred, which is due to the absence of LH stimulation. Thus, the mechanisms of CITED4 in regulating GC proliferation and apoptosis should be explored further.

Cell cycle regulation represents a major regulatory mechanism of cell growth, which is typically regulated by several types of cyclins, such as cyclin-dependent kinase (CDK) and cyclin-dependent kinase inhibitor (CKI) (Aylon \& Kupiec 2005, Buck et al. 2009, Lavi et al. 2011). CITED1 downregulation suppressed cell proliferation by inducing cell cycle arrest in the G2/M phase, which was accompanied by downregulation of CDK1 and CyclinB1 expression (Jiang et al. 2016). Consistent with these observations, our results demonstrated that CITED4 overexpression induced cell cycle transition from $\mathrm{S}$ to $\mathrm{G} 2 / \mathrm{M}$ phase, which was accompanied by the upregulation of CDK1 and Cyclin B1 expression. These results supported the hypothesis that activation of the CyclinB1-CDK1 complex is required for cells to pass the G2/M restriction point (Sun et al. 2019). CITED4 knockdown did not affect cell cycle distribution or the mRNA expression of Cyclin B1, CKD4, and Cyclin D1 in GCs, since the activation of Cyclin D1-CDK4 complexes is required for cells to pass the G1/S restriction point (Dong et al. 2001). However, CITED4 knockdown can inhibit cell proliferation by moderately inhibiting the cell cycle at the G2/M phase in colorectal cancer cells (Rogers et al. 2016). This difference between our results and those of the previous study can be attributed to variations in cell types and treatment methods.

Apoptosis is a precisely controlled process regulated by members of the caspase and $\mathrm{Bcl}-2$ families. In the intrinsic apoptosis pathway, pro-apoptotic factors in mitochondria are released following cell cycle arrest or damage to cellular DNA, leading to apoptosis induction by the activation of caspase3. Meanwhile, caspase 8 activation by death receptors in the extrinsic apoptosis pathway can activate caspase3 directly or indirectly via activation of Bid in the intrinsic apoptosis pathway (Kiraz et al. 2016). BCl-2 plays a crucial role in the inhibition of apoptosis (Spampanato et al. 2012), and the ratio of BAX to Bcl-2 is typically regarded as an important indicator of apoptosis (Korsmeyer et al. 1993). Here, although CITED4 overexpression significantly affected the gene expression levels of $\mathrm{BAX}, \mathrm{Bcl}-2$, and caspase8, only a minor reduction was observed in the apoptosis rate, with no changes observed in caspase 3 gene expression. CITED4 knockdown significantly increased the apoptosis rate and the gene expression levels of BAX, caspase8, and caspase3. Moreover, our findings demonstrate that the ratio of $\mathrm{BAX} / \mathrm{Bcl}-2$ was negatively correlated with CITED4 expression in GCs. Thus, low CITED4 expression might trigger the apoptotic cascade in Hu sheep GCs; meanwhile, CITED4 might regulate GC apoptosis via a mechanism initiated by the regulation of apoptosis-related genes, primarily BAX and caspase8.

Ovarian steroids play essential roles in mammalian folliculogenesis. Particularly, the steroidogenesis process in GCs is vital during follicular development (Sanchez etal. 2016). C/EBP $\beta$ knockdown in porcine GCs significantly inhibited $\mathrm{P}_{4}$ production (Mizutani et al. 2014, Zhen et al. 2014), which is consistent with our results demonstrating that CITED4 expression in GCs of Hu sheep antral follicles significantly induced $\mathrm{P}_{4}$ secretion. $\mathrm{P}_{4}$ biosynthesis is a complex process modulated by multiple proteins and enzymes including StAR and 33-HSD (Yao et al. 2017b), which can positively upregulate the production of $\mathrm{P}_{4}$ (Mizutani et al. 2015). In this study, CITED4 knockdown in GCs significantly downregulated the mRNA levels of StAR and $3 \beta-H S D$. C/EBP $\beta$ knockdown in porcine GCs significantly was shown to inhibit the production of $\mathrm{P}_{4}$ and $E_{2}$ (Zhen et al. 2014). In the present study, we found that CITED4 expression demonstrated no significant effect on $E_{2}$ secretion. This finding is likely due to the absence of CYP17A1 (Cytochrome P450 17A1) in sheep GCs, and the fact that we did not add androgen precursor to the culture media (Padmanabhan et al. 2014). These observations demonstrated that CITED4 may be involved in the regulation of steroidogenesis in Hu sheep GCs.

In conclusion, this study demonstrated that CITED4 is primarily expressed in ovarian GCs of antral follicles, and was induced after LH treatment. CITED4 overexpression significantly enhanced the expression of ovulationrelated gene in GCs following $\mathrm{LH}$ treatment, suggesting that CITED4 overexpression moderately augmented the responses of GCs to LH. In contrast, knockdown of CITED4 in GCs decreased PGE2-induced LH-target genes. Moreover, the stimulation of CITED4 mRNA expression by LH or PGE2 was blocked by ERK1/2 inhibition (U0126), suggesting that CITED4 is a downstream target of the ERK1/2 pathway in sheep GCs. It was also determined that 
CITED4 could regulate GC proliferation, apoptosis, and $\mathrm{P}_{4}$ production in Hu sheep by regulating the expression of genes associated with the cell cycle, apoptosis, and steroid hormones, thus revealing that CITED4 plays an important role in follicular development. Overall, the current study sheds light on the biologic significance of CITED4 in Hu sheep GCs; however, more studies are required to further explore these mechanisms.

\section{Declaration of interest}

The authors declare that there is no conflict of interest that could be perceived as prejudicing the impartiality of the research reported.

\section{Funding}

This study was financially supported by the earmarked fund for the National Natural Science Foundation of China (31872357; 32002174) and the Research Funds for Young Scholars of Nanjing Agricultural University (804005).

\section{Author contribution statement}

X Y: Conceptualization, Investigation, Visualization, Writing, Original Draft. M A S: Validation, Formal analysis, Data Curation. X S: Conceptualization, Investigation, Visualization. Z W: Validation, Formal analysis, Review and Editing. F M: Visualization; Resources. X L: Resources. Y B: Resources. Y Z: Review and Editing. Y F: Resources. F W: Supervision, Funding acquisition. All authors have read and approved the final manuscript.

\section{Acknowledgements}

The authors sincerely thank Hengyu Fan and Yinli Zhang from Zhejiang University for their full support.

\section{References}

Aylon Y \& Kupiec M 2005 Cell cycle-dependent regulation of doublestrand break repair: a role for the CDK. Cell Cycle 4 259-261. (https:// doi.org/10.4161/cc.4.2.1429)

Ben-Ami I, Freimann S, Armon L, Dantes A, Strassburger D, Friedler S, Raziel A, Seger R, Ron-El R \& Amsterdam A 2006 PGE2 up-regulates EGFlike growth factor biosynthesis in human granulosa cells: new insights into the coordination between PGE2 and LH in ovulation. Molecular Human Reproduction 12 593-599. (https://doi.org/10.1093/molehr/gal068)

Buck SH, Chiu D \& Saito RM 2009 The cyclin-dependent kinase inhibitors, cki-1 and cki-2, act in overlapping but distinct pathways to control cell cycle quiescence during C. elegans development. Cell Cycle 8 2613-2620. (https://doi.org/10.4161/cc.8.16.9354)

Carletti MZ \& Christenson LK 2009 Rapid effects of LH on gene expression in the mural granulosa cells of mouse periovulatory follicles. Reproduction 137 843-855. (https://doi.org/10.1530/REP-08-0457)

Casarini L, Riccetti L, De Pascali F, Gilioli L, Marino M, Vecchi E, Morini D, Nicoli A, La Sala GB \& Simoni M 2017 Estrogen modulates specific life and death signals induced by LH and hCG in human primary granulosa cells in vitro. International Journal of Molecular Sciences 18 926. (https:// doi.org/10.3390/ijms18050926)
De Cesaro MP, Dos Santos JT, Ferst JG, Nobrega Jr JE, Rosa P, Rovani MT, Ilha GF, Bohrer RC, Ferreira R, Gasperin BG et al. 2018 Natriuretic peptide system regulation in granulosa cells during follicle deviation and ovulation in cattle. Reproduction in Domestic Animals 53 710-717. (https://doi.org/10.1111/rda.13161)

Dong Y, Sui L, Sugimoto K, Tai Y \& Tokuda M 2001 Cyclin D1-CDK4 complex, a possible critical factor for cell proliferation and prognosis in laryngeal squamous cell carcinomas. International Journal of Cancer 95 209-215.(https://doi.org/10.1002/1097-0215(20010720)95:4<209::aidijc1036>3.0.co;2-r)

Espey LL \& Richards JS 2002 Temporal and spatial patterns of ovarian gene transcription following an ovulatory dose of gonadotropin in the rat. Biology of Reproduction 67 1662-1670. (https://doi.org/10.1095/ biolreprod.102.005173)

Fan HY, Liu Z, Shimada M, Sterneck E, Johnson PF, Hedrick SM \& Richards JS 2009 MAPK3/1 (ERK1/2) in ovarian granulosa cells are essential for female fertility. Science 324 938-941. (https://doi.org/10.1126/science.1171396)

Fan HY, Liu Z, Johnson PF \& Richards JS 2011 CCAAT/enhancer-binding proteins (C/EBP)-alpha and -beta are essential for ovulation, luteinization, and the expression of key target genes. Molecular Endocrinology 25 253-268. (https://doi.org/10.1210/me.2010-0318)

Filicori M, Cognigni GE, Samara A, Melappioni S, Perri T, Cantelli B, Parmegiani L, Pelusi G \& Dealoysio D 2002 The use of LH activity to drive folliculogenesis: exploring uncharted territories in ovulation induction. Human Reproduction Update 8 543-557. (https://doi. org/10.1093/humupd/8.6.543)

Gupta C, Chapekar T, Chhabra Y, Singh P, Sinha S \& Luthra K 2012 Differential response to sustained stimulation by hCG and LH on goat ovarian granulosa cells. Indian Journal of Medical Research 135 331-340. (https://doi.org/10.4103/0971-5916.93429)

Hackbart KS, Bender RW, Carvalho PD, Vieira LM, Dresch AR, Guenther JN, Gencoglu H, Nascimento AB, Shaver RD \& Wiltbank MC 2017 Effects of propylene glycol or elevated luteinizing hormone during follicle development on ovulation, fertilization, and early embryo development. Biology of Reproduction 97 550-563. (https://doi. org/10.1093/biolre/iox050)

Jiang JT, Ma YN, Gao XY, Jin YF, Ma XC, Yan WJ, Zhang H, Wang W, Tian T, Zhao QQ et al. 2016 Downregulation of Cited1 suppresses cell proliferation by inducing G2/M arrest of the cell cycle in non-small-cell lung cancer cell lines. International Journal of Clinical and Experimental Pathology 9 11583-11590.

Kiraz Y, Adan A, Kartal Yandim M \& Baran Y 2016 Major apoptotic mechanisms and genes involved in apoptosis. Tumour Biology 37 8471-8486. (https://doi.org/10.1007/s13277-016-5035-9)

Korsmeyer SJ, Shutter JR, Veis DJ, Merry DE \& Oltvai ZN 1993 Bcl-2/ Bax - a rheostat that regulates an antioxidant pathway and cell-death. Seminars in Cancer Biology 4 327-332. (https://doi.org/10.1016/01678140(93)90160-A)

Lavi O, Ginsberg D \& Louzoun Y 2011 Regulation of modular cyclin and CDK feedback loops by an E2F transcription oscillator in the mammalian cell cycle. Mathematical Biosciences and Engineering 8 445-461. (https://doi.org/10.3934/mbe.2011.8.445)

Lee S, Shuman JD, Guszczynski T, Sakchaisri K, Sebastian T, Copeland TD, Miller M, Cohen MS, Taunton J, Smart RC et al. 2010 RSK-mediated phosphorylation in the C/EBP\{beta\} leucine zipper regulates DNA binding, dimerization, and growth arrest activity. Molecular and Cellular Biology 30 2621-2635. (https://doi.org/10.1128/MCB.00782-09)

Matsuda F, Inoue N, Manabe N \& Ohkura S 2012 Follicular growth and atresia in mammalian ovaries: regulation by survival and death of granulosa cells. Journal of Reproduction and Development 58 44-50. (https://doi.org/10.1262/jrd.2011-012)

McGee EA \& Hsueh AJ 2000 Initial and cyclic recruitment of ovarian follicles. Endocrine Reviews 21 200-214. (https://doi.org/10.1210/ edrv.21.2.0394)

Miake J, Notsu T, Higaki K, Hidaka K, Morisaki T, Yamamoto K \& Hisatome I 2017 Cited4 is related to cardiogenic induction and maintenance of proliferation capacity of embryonic stem cell-derived cardiomyocytes during in vitro cardiogenesis. PLOS ONE 12 e0183225. (https://doi.org/10.1371/journal.pone.0183225)

Mizutani T, Ju Y, Imamichi Y, Osaki T, Yazawa T, Kawabe S, Ishikane S, Matsumura T, Kanno M, Kamiki Y et al. 2014 C/EBP $\beta$ (CCAAT/ enhancer-binding protein $\beta$ ) mediates progesterone production through 
transcriptional regulation in co-operation with SF-1 (steroidogenic factor-1). Biochemical Journal 460 459-471. (https://doi.org/10.1042/ BJ20131522)

Mizutani T, Ishikane S, Kawabe S, Umezawa A \& Miyamoto K 2015 Transcriptional regulation of genes related to progesterone production. Endocrine Journal 62 757-763. (https://doi.org/10.1507/endocrj.EJ150260)

Newman DM, Jones PL \& Ingram BA 2008 Age-related changes in ovarian characteristics, plasma sex steroids and fertility during pubertal development in captive female Murray cod Maccullochella peelii peelii. Comparative Biochemistry and Physiology: Part A, Molecular and Integrative Physiology 150 444-451. (https://doi.org/10.1016/j. cbpa.2008.05.005)

Niringiyumukiza JD, Cai H \& Xiang W 2018 Prostaglandin E2 involvement in mammalian female fertility: ovulation, fertilization, embryo development and early implantation. Reproductive Biology and Endocrinology 16 43. (https://doi.org/10.1186/s12958-018-0359-5)

Padmanabhan V, Salvetti NR, Matiller V \& Ortega HH 2014 Developmental programming: prenatal steroid excess disrupts key members of intraovarian steroidogenic pathway in sheep. Endocrinology 155 3649-3660.(https://doi.org/10.1210/en.2014-1266)

Palermo R 2007 Differential actions of FSH and LH during folliculogenesis. Reproductive Biomedicine Online 15 326-337. (https://doi.org/10.1016/ S1472-6483(10)60347-1)

Park JY, Su YQ, Ariga M, Law E, Jin SL \& Conti M 2004 EGF-like growth factors as mediators of LH action in the ovulatory follicle. Science $\mathbf{3 0 3}$ 682-684.(https://doi.org/10.1126/science.1092463)

Rogers MA, Kalter V, Marcias G, Zapatka M, Barbus S \& Lichter P 2016 CITED4 gene silencing in colorectal cancer cells modulates adherens/ tight junction gene expression and reduces cell proliferation. Journal of Cancer Research and Clinical Oncology 142 225-237. (https://doi. org/10.1007/s00432-015-2011-5)

Sanchez AM, Somigliana E, Vercellini P, Pagliardini L, Candiani M \& Vigano P 2016 Endometriosis as a detrimental condition for granulosa cell steroidogenesis and development: from molecular alterations to clinical impact. Journal of Steroid Biochemistry and Molecular Biology 155 35-46. (https://doi.org/10.1016/j.jsbmb.2015.07.023)

Shimada M \& Yamashita Y 2011 The key signaling cascades in granulosa cells during follicular development and ovulation process. Journal of Mammalian Ova Research 28 25-31. (https://doi.org/10.1274/jmor.28.25)

Skory RM, Xu Y, Shea LD \& Woodruff TK 2015 Engineering the ovarian cycle using in vitro follicle culture. Human Reproduction 30 1386-1395. (https://doi.org/10.1093/humrep/dev052)

Spampanato C, De Maria S, Sarnataro M, Giordano E, Zanfardino M, Baiano S, Carteni M \& Morelli F 2012 Simvastatin inhibits cancer cell growth by inducing apoptosis correlated to activation of Bax and downregulation of BCL-2 gene expression. International Journal of Oncology 40 935-941. (https://doi.org/10.3892/ijo.2011.1273)

Sun J, Du Y, Song Q, Nan J, Guan P, Guo J, Wang X, Yang J \& Zhao C 2019 E2F is required for STAT3-mediated upregulation of cyclin B1 and $\mathrm{Cdc} 2$ expressions and contributes to G2-M phase transition. Acta Biochimica and Biophysica Sinica 51 313-322. (https://doi.org/10.1093/ abbs/gmy174)

Tang H, Liu Y, Li J, Li G, Chen Y, Yin Y, Guo Y, Cheng CH, Liu X \& Lin H 2017 LH signaling induced ptgs2a expression is required for ovulation in zebrafish. Molecular and Cellular Endocrinology 447 125-133. (https:// doi.org/10.1016/j.mce.2017.02.042)

Tosca L, Rame C, Chabrolle C, Tesseraud S \& Dupont J 2010 Metformin decreases IGF1-induced cell proliferation and protein synthesis through
AMP-activated protein kinase in cultured bovine granulosa cells. Reproduction 139 409-418. (https://doi.org/10.1530/REP-09-0351)

Yahata T, Takedatsu H, Dunwoodie SL, Bragança J, Swingler T, Withington SL, Hur J, Coser KR, Isselbacher KJ, Bhattacharya S et al. 2002 Cloning of mouse Cited4, a member of the CITED family p300/CBP-binding transcriptional coactivators: induced expression in mammary epithelial cells. Genomics 80 601-613. (https://doi. org/10.1006/geno.2002.7005)

Yamashita Y, Kawashima I, Yanai Y, Nishibori M, Richards JS \& Shimada M 2007 Hormone-induced expression of tumor necrosis factor alpha-converting enzyme/A disintegrin and metalloprotease-17 impacts porcine cumulus cell oocyte complex expansion and meiotic maturation via ligand activation of the epidermal growth factor receptor. Endocrinology 148 6164-6175. (https://doi.org/10.1210/en.2007-0195)

Yao X, Yang H, Zhang Y, Ren C, Nie H, Fan Y, Zhou W, Wang S, Feng X \& Wang F 2017a Characterization of GALNTL5 gene sequence and expression in ovine testes and sperm. Theriogenology 95 54-61. (https:// doi.org/10.1016/j.theriogenology.2017.02.018)

Yao X, Zhang G, Guo Y, Ei-Samahy M, Wang S, Wan Y, Han L, Liu Z, Wang F \& Zhang Y 2017b Vitamin D receptor expression and potential role of vitamin $\mathrm{D}$ on cell proliferation and steroidogenesis in goat ovarian granulosa cells. Theriogenology 102 162-173. (https://doi. org/10.1016/j.theriogenology.2017.08.002)

Yao X, Wang Z, El-Samahy MA, Ren C, Liu Z, Wang F \& You P 2020 Roles of vitamin D and its receptor in the proliferation and apoptosis of luteinised granulosa cells in the goat. Reproduction, Fertility, and Development 32 335-348. (https://doi.org/10.1071/RD18442)

Yuan X, Zhou X, He Y, Zhong Y, Zhang A, Zhang Z, Zhang H \& Li J 2018 C/EBP $\beta$ promotes STAT3 expression and affects cell apoptosis and proliferation in porcine ovarian granulosa cells. Genes 9 295. (https:// doi.org/10.3390/genes9060295)

Zhang YL, Xia Y, Yu C, Richards JS, Liu J \& Fan HY 2014 CBP-CITED4 is required for luteinizing hormone-triggered target gene expression during ovulation. Molecular Human Reproduction 20 850-860. (https://doi. org/10.1093/molehr/gau040)

Zhang GM, Deng MT, Zhang YL, Fan YX, Wan YJ, Nie HT, Wang ZY, Wang F \& Lei ZH 2016 Effect of PGC-1 alpha overexpression or silencing on mitochondrial apoptosis of goat luteinized granulosa cells. Journal of Bioenergetics and Biomembranes 48 493-507. (https://doi.org/10.1007/ s10863-016-9684-6)

Zhang GM, Deng MT, Lei ZH, Wan YJ, Nie HT, Wang ZY, Fan YX, Wang F \& Zhang YL 2017 Effects of NRF1 on steroidogenesis and apoptosis in goat luteinized granulosa cells. Reproduction 154 111-122. (https://doi. org/10.1530/REP-16-0583)

Zhen YH, Wang L, Riaz H, Wu JB, Yuan YF, Han L, Wang YL, Zhao Y, Dan Y \& Huo LJ 2014 Knockdown of CEBPbeta by RNAi in porcine granulosa cells resulted in $\mathrm{S}$ phase cell cycle arrest and decreased progesterone and estradiol synthesis. Journal of Steroid Biochemistry and Molecular Biology 143 90-98. (https://doi.org/10.1016/j.jsbmb.2014.02.013)

Received 31 July 2020

First decision 25 August 2020

Revised manuscript received 25 November 2020

Accepted 1 December 2020 